\title{
Focal cryotherapy: step by step technique description
}

\author{
Cristina Redondo ${ }^{1}$, Victor Srougi ${ }^{2}$, José Batista da Costa ${ }^{3}$, Mohammed Baghdad ${ }^{4}$, Guillermo Velilla ${ }^{3}$, \\ Igor Nunes-Silva ${ }^{3}$, Sebastien Bergerat ${ }^{3}$, Silvia Garcia-Barreras ${ }^{3}$, François Rozet ${ }^{3}$, Alexandre Ingels ${ }^{4}$, \\ Marc Galiano ${ }^{4}$, Rafael Sanchez-Salas ${ }^{4}$, Eric Barret ${ }^{4}$, Xavier Cathelineau ${ }^{4}$ \\ ${ }^{1}$ Hospital Universitario de Getafe - Servicio de Urologia, Getafe, Spain; ${ }^{2}$ Hospital das Clínicas da Facul- \\ dade de Medicina da USP - Urologia, São Paulo, Brasil; ${ }^{3}$ Institut Mutualiste Montsouris Ringgold stan- \\ dard institution, Paris, Ille-de-France, France; ${ }^{4}$ L'Institut Mutualiste Montsouris - Urology, Paris, France
}

\begin{abstract}
Introduction and objective: Focal cryotherapy emerged as an efficient option to treat favorable and localized prostate cancer (PCa). The purpose of this video is to describe the procedure step by step.

Materials and methods: We present the case of a 68 year-old man with localized PCa in the anterior aspect of the prostate. Results: The procedure is performed under general anesthesia, with the patient in lithotomy position. Briefly, the equipment utilized includes the cryotherapy console coupled with an ultrasound system, argon and helium gas bottles, cryoprobes, temperature probes and an urethral warming catheter. The procedure starts with a real-time trans-rectal prostate ultrasound, which is used to outline the prostate, the urethra and the rectal wall. The cryoprobes are pretested and placed in to the prostate through the perineum, following a grid template, along with the temperature sensors under ultrasound guidance. A cystoscopy confirms the right positioning of the needles and the urethral warming catheter is installed. Thereafter, the freeze sequence with argon gas is started, achieving extremely low temperatures $\left(-40^{\circ} \mathrm{C}\right)$ to induce tumor cell lysis. Sequentially, the thawing cycle is performed using helium gas. This process is repeated one time. Results among several series showed a biochemical disease-free survival between 71-93\% at 9-70 month- follow-up, incontinence rates between 0-3.6\% and erectile dysfunction between 0-42\% (1-5).

Conclusions: Focal cryotherapy is a feasible procedure to treat anterior PCa that may offer minimal morbidity, allowing good cancer control and better functional outcomes when compared to whole-gland treatment.
\end{abstract}

\section{CONFLICT OF INTEREST}

None declared.

\section{REFERENCES}

1. Sivaraman A, Barret E. Focal Therapy for Prostate Cancer: An "À la Carte" Approach. Eur Urol. 2016;69:973-5.

2. Nguyen HD, Allen BJ, Pow-Sang JM. Focal cryotherapy in the treatment of localized prostate cancer. Cancer Control. 2013;20:177-80.

3. Tay KJ, Polascik TJ. Focal Cryotherapy for Localized Prostate Cancer. Arch Esp Urol. 2016;69:317-26.
4. Ward JF, Jones JS. Focal cryotherapy for localized prostate cancer: a report from the national Cryo On-Line Database (COLD) Registry. BJU Int. 2012;109:1648-54.

5. Babaian RJ, Donnelly B, Bahn D, Baust JG, Dineen M, Ellis $D$, et al. Best practice statement on cryosurgery for the treatment of localized prostate cancer. J Urol. 2008;180:1993-2004. 


\section{ARTICLE INFO}

Available at: http://www.intbrazjurol.com.br/video-section/20160664_Redondo_et_al Int Braz J Urol. 2017; 43 (Video \#14): 995-6

Submitted for publication:

December 19, 2016

Correspondence address:

Victor Srougi, MD

Accepted after revision:

March 20, 2017

Departamento de Urologia

Published as Ahead of Print:

June 12, 2017

Hospital das Clínicas da Faculdade de Medicina da USP

Avenida Eneas de Carvalho Aguiar, 255

São Paulo, SP 01409003, Brasil

E-mail: vsrougi@gmail.com 